\title{
The Status of First Aid Skills Mastery and Training Preferences of College Students: A Cross-Sectional Survey
}

\author{
Jin Xiao Sheng ${ }^{1}$, Chen Hai Tang ${ }^{2}$, Zhang Hao ${ }^{3}$, Ye Kan ${ }^{4}$, Zhang Gai \\ ${ }^{1}$ Professor, ${ }^{3,4,5}$ Associate Professor, Department of Emergency Medicine, Medical Emergency Service of \\ Wenzhou, Zhejiang Province, China \\ ${ }^{2}$ Associate Professor of Nursing, Cangnan County People's Hospital, Wenzhou City, Zhejiang Province, China \\ Corresponding Author: Jin Xiao Sheng
}

DOI: https://doi.org/10.52403/ijhsr.20220109

\begin{abstract}
Objective: Bystander first aid can improve the survival rate after out-of-hospital cardiac arrest or trauma, College students are potential bystanders of first aid in society. In the research, we aim to determine the universality of first aid training and the mastery of first aid skills among college students in order to implement first aid.

Methods: From January to October 2021, carry out questionnaire surveys by WeChat push, A random cross-sectional study was conducted on students from five universities in Wenzhou. In order to understand the knowledge and skills of first aid, Respondents accepted the first aid scenario that answered two hypotheses.

Results: Among the 1,171 college students interviewed. Among them, 37.23\% are males and $62.77 \%$ are females; $78.31 \%$ have first aid training experience, and $21.69 \%$ have no first aid training experience; $71 \%$ of college students acquire theoretical knowledge and practical skills through first aid training conducted by the Red Cross, medical emergency centers or hospitals, etc. $22 \%$ of college students study through the information network; All college students interviewed expressed their willingness to participate in first aid training. But $21.69 \%$ of college students have not received first aid training, The reason for the inability to participate in the training is that they do not understand the ways to participate in first aid training, accounting for 37.01\%; Lack of confidence accounted for $19.69 \%$, and lack of time accounted for $35.04 \%$; In the hypothetical emergency scene, In the male group, $48.96 \%$ were willing to treat the injured, and $36.19 \%$ in the female group. There is a statistical difference between the two $(\mathrm{P}<0.01)$; The junior college student group and the undergraduate student group are $28.09 \%$ and $44.09 \%$ separately. The medical professional group and the students with the first aid training group are $60.4 \%$ and $43.51 \%$ separately, The willingness to implement first aid has a clear advantage over the non-medical and non-trained two groups. The comparison between the two groups was statistically significant $(\mathrm{P}<0.01)$. The first aid skills are well mastered: chest compression $46.19 \%$, judgment awareness $35.95 \%$, hemostasis bandaging $32.88 \%$, The worse ones were artificial respiration $24.67 \%$, open airway $23.56 \%$, and fracture fixation $8.96 \%$.

Conclusion: College students have a positive attitude towards learning first aid knowledge. However, it was found that the first aid skills were not well mastered, and the training was insufficient. Colleges and universities should provide first aid-related courses, extracurricular intensive training and other methods, Increase the knowledge of college students to deal with emergencies and improve basic first aid skills. Incorporating first aid skills training into university curricula and implementing it is a longterm strategy. Improve college students' awareness of first aid knowledge to obtain better social benefits.
\end{abstract}

Key Words: Attitude, First aid skills, college student training 
Jin Xiao Sheng et.al. The status of first aid skills mastery and training preferences of college students: a crosssectional survey.

\section{INTRODUCTION}

Sudden cardiac arrest and accidental injury have caused global concern because it is a fatal public health problem worldwide. Survival may depend on rapid and correct first aid by bystanders. Early implementation of cardiopulmonary resuscitation (CPR) is essential to improve the survival chances of patients without-ofhospital cardiac arrest and to improve their nervous system and health ${ }^{[1]}$. For trauma patients, if bystanders provide airway clearance and bleeding control, It can avoid $1.8-5 \%$ of traumatic deaths ${ }^{[2]}$. In Norway, $54-76 \%$ of OHCA victims receive bystander CPR; $62-81 \%$ of trauma patients receive basic life support (BLS) provided by bystanders ${ }^{[3-5]}$.

Bystanders who have received first aid training are more likely to provide first aid. First aid popularization training is related to the public providing better first aid quality ${ }^{[4,6]}$ Therefore, providing first aid education to the public is considered an important means to improve OHCA and trauma outcomes ${ }^{[2,7,8]}$. Since there may be many difficulties in first aid training for the entire society, College students are an important part of the public volunteer members, mastering first aid skills is the basic requirement of personal literacy, It is very meaningful to investigate the first aid training and mastery of first aid skills of college students.

The purpose of this research is to assess the level of first aid knowledge of college students and determine relevant factors. Willingness to implement first aid behavior and first aid training preferences, attitudes and obstacles.

\section{MATERIALS AND METHODS}

From January to October 2021, the questionnaire survey will be carried out by WeChat push. A random cross-sectional study was conducted on students from five universities in Wenzhou. Inclusion criteria: (1) Full-time university students; (2) Voluntary participation in online questionnaire surveys. All students understood the purpose of the research and completed the electronic questionnaire by scanning the WeChat QR code. All students participating in the survey signed an informed consent form before filling out the questionnaire. Each completed questionnaire is assigned a unique number. Incomplete and conflicting answers are considered invalid.

On the basis of reviewing a large number of relevant literature $\mathrm{e}^{[9,10]}$, Selfdesigned and produced a questionnaire titled

《Mastery of First Aid Skills of College Students $\rangle$. The questionnaire consists of two parts: Part I collects demographic information, including age, gender, profession, willingness to implement first aid, ways to obtain first aid knowledge, training experience, etc. In Part II, a hypothetical first aid scenario is proposed, Scenario 1 involves non-cardiac arrest trauma, and scenario 2 involves cardiopulmonary resuscitation. Interviewees were asked what they would do in these situations, and allow them to freely choose the answer, and count the first aid measures mentioned by the interviewees. In this case, the term "first aid" includes resuscitation and non-resuscitation, basic life support and trauma treatment ${ }^{[11]}$. The validity of the content of the questionnaire was reviewed and approved by three first aid experts

Use SPSS 20.0 statistical software to analyze the data, using descriptive analysis, Chi-square test, $\mathrm{P}<0.05$ as the difference are statistically significant.

\section{RESULTS}

A total of 1,193 questionnaires were collected and completed, exclude 22 questionnaires with incomplete or contradictory answers, Include 1171 questionnaires for final analysis. The age range of the interviewed college students was 18 to be 26 years old, of which $37.23 \%$ were males and $62.77 \%$ were females; College degree is $40.73 \%$, bachelor degree and above is $59.27 \%$; $43.12 \%$ are medical or related majors, and $56.88 \%$ are nonmedicine-related majors; $78.31 \%$ had 
Jin Xiao Sheng et.al. The status of first aid skills mastery and training preferences of college students: a crosssectional survey.

experience in first aid training, and $21.69 \%$ had no experience in first aid training (Table 1).

Table 1 Basic information distribution characteristics and training experience

\begin{tabular}{|l|l|l|}
\hline & Number & percentage (\%) \\
\hline gender & & \\
\hline male & 436 & 37.23 \\
\hline Female & 735 & 62.77 \\
\hline Education & & \\
\hline Specialist & 477 & 40.73 \\
\hline Bachelor degree and above & 694 & 59.27 \\
\hline Professional & & \\
\hline Medical related majors & 505 & 43.12 \\
\hline Non-medical related majors & 666 & 56.88 \\
\hline First aid training experience & & \\
\hline have & 917 & 78.31 \\
\hline no & 254 & 21.69 \\
\hline
\end{tabular}

Figure 1 : Main ways to acquire first aid knowledge $39,3 \%$

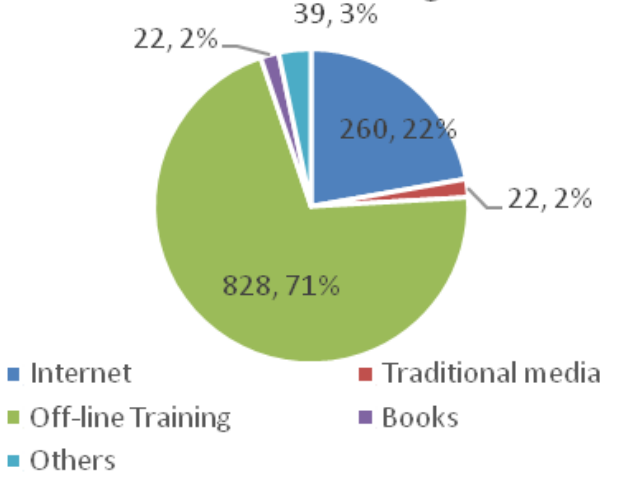

As shown in Figure 1, $71 \%$ of college students acquire theoretical knowledge and practical skills through first aid training conducted by the Chinese Red Cross, medical emergency centers or hospitals, etc. $22 \%$ of college students study through the information network; $2 \%$ for learning through books and traditional media; 3\% for other forms of learning.

The interviewed college students received four hours of first aid training for $6 \%$; eight hours for $22 \%$; 16 hours for $72 \%$. $33 \%$ of the respondents received the last training for more than two years.

1171 interviewees all expressed their willingness to participate in first aid training. However, 254 respondents (21.69\%) said they had not received first aid training. The main reasons for not being able to participate in the training: $37.01 \%$ of the interviewed college students did not understand the way to participate in first aid training; lack of confidence 19.69\%; lack of time $35.04 \%$; health reasons $1.57 \%$ (Table 2).

Table 2 Reasons for not participating in first aid training

\begin{tabular}{|l|l|l|}
\hline factor & Number & percentage (\%) \\
\hline $\begin{array}{l}\text { Not sure where to take the } \\
\text { course }\end{array}$ & 94 & 37.01 \\
\hline lack of confidence & 50 & 19.69 \\
\hline Lack of time & 89 & 35.04 \\
\hline $\begin{array}{l}\text { Physical condition (health } \\
\text { reason) }\end{array}$ & 4 & 1.57 \\
\hline other & 17 & 6.69 \\
\hline total & 254 & 100.00 \\
\hline
\end{tabular}

Table 3 Willingness to implement first aid

\begin{tabular}{|l|l|l|l|}
\hline & Number/total (\%) & $\chi^{2}$ & $\begin{array}{l}\text { p } \\
\text { value }\end{array}$ \\
\hline gender & & & \\
\hline male & $214 / 436(48.96 \%)$ & & \\
\hline Female & $226 / 735(36.19 \%)$ & 39.22 & $<0.01$ \\
\hline Education & & & \\
\hline Specialist & $134 / 477(28.09 \%)$ & & \\
\hline $\begin{array}{l}\text { Bachelor degree and } \\
\text { above }\end{array}$ & $306 / 694(44.09 \%)$ & 18.23 & $<0.01$ \\
\hline Professional & & & \\
\hline medicine & $305 / 505(60.4 \%)$ & & \\
\hline Non-medical & $135 / 666(20.27 \%)$ & 197.15 & $<0.01$ \\
\hline $\begin{array}{l}\text { First aid training } \\
\text { experience }\end{array}$ & & & \\
\hline have & $399 / 917(43.51 \%)$ & & \\
\hline no & $41 / 254(16.14 \%)$ & 63.52 & $<0.01$ \\
\hline
\end{tabular}

Table 4 Proportion of first aid skills mastery

\begin{tabular}{|l|l|l|}
\hline First aid skills & Number & percentage (\%) \\
\hline Judgment consciousness & $421 / 1171$ & 35.95 \\
\hline Check breathing & $305 / 1171$ & 26.04 \\
\hline Chest compressions & $541 / 1171$ & 46.19 \\
\hline Open airway & $276 / 1171$ & 23.56 \\
\hline Artificial respiration & $289 / 1171$ & 24.67 \\
\hline Restore position & $372 / 1171$ & 31.76 \\
\hline Hemostatic bandaging & $385 / 1171$ & 32.88 \\
\hline Fracture fixation & $105 / 1171$ & 8.96 \\
\hline Airway obstruction removed & $328 / 1171$ & 28.01 \\
\hline
\end{tabular}

As shown in Table 3, Among the interviewed college students, the male group actively willing to treat the wounded was $48.96 \%$, and the female group was $36.19 \%$. There is a difference between the two $(\mathrm{P}<0.01)$; The junior college student group and the undergraduate student group are $28.09 \%$ and $44.09 \%$ respectively. The medical professional group and the students with the first aid training group are $60.4 \%$ and $43.51 \%$ respectively, the willingness to implement first aid has a clear advantage over the non-medical and non-trained two groups. The comparison between the two groups was statistically significant (P $<0.01)$. 
Jin Xiao Sheng et.al. The status of first aid skills mastery and training preferences of college students: a crosssectional survey.

In order to understand first aid knowledge and skills, the interviewed college students accepted two hypothetical first aid scenarios. Only $1.5 \%$ of people correctly mastered all first aid skills. The first aid skills are well mastered: chest compression $46.19 \%$, judgment awareness $35.95 \%$, hemostasis bandaging $32.88 \%$, The poor masters were artificial respiration $24.67 \%$, open airway $23.56 \%$, and fracture fixation $8.96 \%$ (Table 4 ).

\section{DISCUSSION}

If the first witness at the scene of accidental injury can implement treatment in a timely and effective manner, it can significantly improve the success rate and survival rate of patient rescue. The vast majority of first witnesses are the general population, and they often miss the best rescue opportunity because they do not understand first aid measures ${ }^{[10]}$. The data of this research shows that $60.4 \%$ of medical majors and $20.27 \%$ of non-medical majors have received first aid training. College students have a low level of mastery of first aid skills, especially nonmedical students, which is consistent with the research results of Qiu Yalin et al. ${ }^{\text {[12] }}$.

$78.3 \%$ of college students have received first aid skills training. Compared with other countries, the proportion of college students receiving training is still lower than expected. For example, $90 \%$ of Norwegians (15 years or older) have received first aid knowledge training ${ }^{[13,14]}$. Active training methods may be the reason for the higher proportion of first aid skills in developed countries. According to the International Federation of Red Cross and Red Crescent Societies, first aid training is a required course in Denmark, France, Germany, Italy and Norway ${ }^{[15]}$, This means that we need more active publicity and promotion of this work.

This study found that $71 \%$ of the students learned first aid skills and practical operations through training provided by the Chinese Red Cross and Medical Emergency Centers. The traditional in person teacher- guided skill training method is still the main method for college students to learn first aid. It may be better to practice the operation experience and master the essentials of first aid technology, and thus become more popular with students. The school-based training program for first aid knowledge has been recognized by the World Health Organization, the Red Cross Society of China and other professional healthcare organizations [16]. Allowing college students to prepare for assistance in encountering accidental injuries can improve the overall response of the area to emergency rescue, thereby increasing the survival rate.

The common reasons given by those who have not received any first aid training are lacked of time (35.04\%), lack of confidence (19.69\%) and unsure where to attend the course (37.01\%). This is also consistent with other local studies ${ }^{[17-19]}$. The author of this study believes that since mobile electronic devices are an indispensable learning tool for college students, Video demonstration through independent online learning is a recommended way to solve the lack of time for first aid training. Alternatively, incorporating first aid knowledge training into school curricula or extracurricular activities for all college students, these operational challenges can be easily overcome. At the same time, further research and improvement of the content of first aid training (cardiopulmonary resuscitation, trauma treatment, other situations), modes (classical teaching, video-based or other teaching) and the length of time provided to students of first aid training will be worthy of future research.

In this study, $60.4 \%$ of the medical professional group and $43.51 \%$ of the college students who have received first aid training have a clear advantage in the willingness to implement first aid than the non-medical professional group and the two groups without training. The interviewed college students believe that it is necessary 
to participate in first-aid course training, and showed a strong willingness to perform first aid in an emergency. Interviewed college students who have received first aid skills training had a better attitude and confidence in implementing first aid measures, which is similar to other studies ${ }^{[20,21]}$. In fact, there may be many factors that hinder college students from implementing first aid measures. The main reason is that they are worried that their first aid ability is not enough; they will cause harm to the patient, lack of confidence, fear the spread of disease and legal disputes and are unwilling to carry out on-site rescue. Consistent with the results of other studies [22]. China formulated relevant laws and regulations in 2017, clearly stating that as long as rescuers perform treatment in good faith, they can be exempted from the responsibility of causing various injuries to patients due to treatment ${ }^{[23]}$, But there are still a lot of people who don't understand China's Good Person Law, and we should promote it to more people.

Although most college students have received first aid training, the answers to the first aid scene are not that exciting. Only $46.19 \%$ of the students suggested starting chest compressions when the patient was found to be unconscious and breathing abnormally. $32.88 \%$ of the students suggested providing hemostatic bandages for the injured, while only $8.96 \%$ provided fracture fixation. This finding should be interpreted with caution, because theoretical knowledge of first aid does not necessarily reflect actual first aid skills. There are also demographic and sociological characteristics such as gender, major, school, grade, and home location that affect the attitude of college students to first aid knowledge and skills, to a certain extent, and may also affect the promotion and implementation of first aid skills ${ }^{[24]}$.

This study has several limitations. For reasons of convenience and economy, the randomly sampled report questionnaire may have selection bias. That is, the number of people who have not received first aid training is relatively small. These factors may reduce the generality of the results. Secondly, the interviewed college students may make different assumptions about the situation described in the first aid scene question. Because what they saw was a fairly brief written description of the emergency scene. There is also a lack of flexibility in the questions in the questionnaire, which may reduce the effectiveness of respondents' answers.

\section{CONCLUSIONS}

The proportion of college students with first aid skills is not ideal, but the proportion of students willing to actively implement first aid is encouraging. The results also show that it is difficult for college students to spend extra time participating in first-aid courses on and off campus during their school years, because the heavy academic burden is a major factor. We recommend that local universities organize campus first aid courses with relevant institutions during the holidays. In addition, universities can consider implementing first aid courses as credit courses, which can be seen as alternatives to certain components of university courses. In short, incorporating first aid skills training into higher-education curricula may be a long-term strategy to extend life-saving benefits to the entire society.

\section{ACKNOWLEDGEMENT}

Thank you Wenzhou Science and Technology Bureau for approving this research (Science and Technology Project Number: R2020062). We express our deep gratitude to all college students who participated in this research.

\section{Conflict of Interest: None}

Source of Funding: None 
Jin Xiao Sheng et.al. The status of first aid skills mastery and training preferences of college students: a crosssectional survey.

\section{REFERENCES}

1. Ng SN, Tang LK, Leung CK, et al. Knowledge and training preference of standard first aid among undergraduates in Hong Kong: A cross-sectional survey. Hong Kong Journal of Emergency Medicine. October 2021.

2. Tannvik TD, Bakke HK, Wisborg T. A systematic literature review on first aid provided by laypeople to trauma victims. Acta Anaesthesiol Scand. 2012;56: 1222-7.

3. Lindner TW, Søreide E, Nilsen OB, Torunn MW, Lossius HM. Good outcome in every fourth resuscitation attempt is achievableAn Utstein template report from the Stavanger region. Resuscitation. 2011;82: 1508-13.

4. Bakke HK, Steinvik T, Eidissen S-I, Gilbert M, Wisborg T. Bystander first aid in trauma - prevalence and quality: a prospective observational study. Acta Anaesthesiol Scand. 2015;59:1187-93.

5. Lund-Kordahl I, Olasveengen TM, Lorem T, Samdal M, Wik L, Sunde K. Improving outcome after out-of-hospital cardiac arrest by strengthening weak links of the local Chain of Survival; quality of advanced life support and post-resuscitation care. Resuscitation. 2010;81:422-6.

6. Tanigawa $\mathrm{K}$, Iwami $\mathrm{T}$, Nishiyama $\mathrm{C}$, Nonogi $H$, Kawamura $T$. Are trained individuals more likely to perform bystander CPR? An observational study. Resuscitation. 2011;82:523-8.

7. Bohn A, Van Aken H, Lukas RP, Weber T, Breckwoldt J. Schoolchildren as lifesavers in Europe - training in cardiopulmonary resuscitation for children. Best Pract Res Clin Anaesthesiol. 2013;27:387-96.

8. Rea TD, Fahrenbruch C, Culley L, Donohoe RT, Hambly C, Innes J, et al. CPR with chest compression alone or with rescue breathing. N Engl J Med. 2010; 363:42333.

9. Lu Cui, Jin Yinghui, Ma Wenjing, et al. Current status of research on students' attitudes towards cardiopulmonary resuscitation[J]. Chinese Nursing Education, 2014,11(7):554-557.

10. Fan Maiying, Zou Lianhong, Liu Xiaoliang, et al. The first eyewitness in Hunan area-an analysis of on-site first aid knowledge needs and willingness[J]. Journal of Clinical Emergency Medicine,2016,17(8):606-609.
11. Shi Mingmin, Xie Xiaojie, Tang Biyun, Shan Pengfei, Zhang Fengjiang, Wang Kai. Discussion on field first aid knowledge and skills as a non-medical undergraduate general education course[J].China Higher Medical Education,2019,(4):29- 30.

12. Qiu Yalin, Hong Yu, Zhang Xianyi. Investigation on the health awareness and behavior of college students[J]. Fight (Sports Forum), 2015(9):38-40.

13. Bakke, HK, Steinvik, T, Angell, J, et al. A nationwide survey of first aid training and encounters in Norway. BMC Emerg Med 2017; 17(1): 6.

14. Håkon Kvåle,Bakke,Tine, Steinvik,Johan, Angell, Torben, Wisborg. A nationwide survey of first aid training and encounters in Norway.[J].BMC emergency medicine,2017,17(1):6.DOI:10.1186/s12873 -017-0116-7.

15. Law and first aid: promoting and protecting life-saving action. Geneva: International Federation of Red Cross and Red Crescent Societies, 2015,

https://disasterlaw.ifrc.org/sites/default/files/ media/disaster_law/2021-

02/First\%20Aid\%20Law\%20Advocacy\%20

Report\%20\%28final\%29.pdf (accessed 3 October 2021).

16. Cheung, B. M., Ho, C., Kou, K. O., Koung, E. E., Lai, K. W., Leow, P. L., \& University of Hong Kong Cardiopulmonary Resuscitation Knowledge Study Group. (2003). Knowledge of cardiopulmonary resuscitation among the public in Hong Kong: Telephone questionnaire survey. Hong Kong Medical Journal, 9, 323-328.

17. Xiong Yongchao,Zhang Xiaohua,Zhao Jianzhong.A comparative study on the training curriculum system of public Red Cross emergency nurses at home and abroad[J].Chinese Public Health Management, 2021,37(4):554-556+559.

18. Lu Cui, Jin Yinghui, Ma Wenjing, et al. Analysis of the status quo of college students' attitude towards cardiopulmonary resuscitation and its influencing factors[J]. Acta Nursing Science ,2015(19):13-17.

19. PanJ . Analysis of the status quo of first aid training for college students[J].The world's latest medical information abstracts (continuous electronic journals),2016,16(40):196-197.

20. Chair, S. Y., Hung, M. S., Lui, J. C., Lee, D. T., Shiu, I. Y., \& Choi, K. C. (2014). Public 
Jin Xiao Sheng et.al. The status of first aid skills mastery and training preferences of college students: a crosssectional survey.

knowledge and attitudes towards cardiopulmonary resuscitation in Hong Kong: Telephone survey. Hong Kong Medical Journal, 20, 126-33.

21. Jamaludin, TSS, Zakaria, MAB, Saidi, S, et al. Knowledge, awareness and attitude of first aid among health sciences university students. Int J Care Scholars 2018; 1(1): 2933.

22. Cui, L. , et al. "An exploration of attitudes toward bystander cardiopulmonary resuscitation in university students in Tianjin, China: A survey. "International Emergency Nursing 24(2016):28-34.

23. Gao Jie, Lin Miaomiao, Wang Feng, et al. The "Good Man Law" was officially implemented to support the good people in China! [J]. Government Legal System, 2017(30): 2.

24. Hu Suzhen,Chang Jinlan,Chen Yan.Comparison of prehospital first aid awareness and training effects among nonmedical college students in Ningbo[J]. Nursing and Rehabilitation,2017,16(4):326329.

How to cite this article: Jin Xiao Sheng, Chen Hai Tang, Zhang Hao et.al. The status of first aid skills mastery and training preferences of college students: a cross-sectional survey. Int $J$ Health Sci Res. 2022; 12(1): 61-67. DOI: https://doi.org/10.52403/ijhsr.20220109 